\title{
Evaluation of bone response to titanium-coated polymethyl methacrylate resin (PMMA) implants by X-ray tomography
}

\author{
Manal M. Shalabi · Johannes G. C. Wolke • \\ Vincent M. J. I. Cuijpers · John A. Jansen
}

Received: 22 June 2006/Accepted: 21 August 2006/Published online: 9 June 2007

(C) Springer Science+Business Media, LLC 2007

\begin{abstract}
High-resolution three-dimensional data about the bone response to oral implants can be obtained by using microfocus computer tomography. However, a disadvantage is that metallic implants cause streaking artifacts due to scattering of X-rays, which prevents an accurate evaluation of the interfacial bone-to-implant contact. It has been suggested that the use of thin titanium coatings deposited on polymeric implants can offer an alternative option for analyzing bone contact using micro-CT imaging. Consequently, the aim of the current study was to investigate bone behavior to titanium-coated polymethylmethacrylate (PMMA) implants by micro-CT and histological evaluation. For the experiment titanium-coated PMMA implants were used. The implants had a machined threaded appearance and were provided with a $400-500 \mathrm{~nm}$ thick titanium coating. The implants were inserted in the right or left tibia of 10 goats. After an implantation period of 12 weeks the implants were retrieved and prepared for micro-computer tomography $(\mu \mathrm{CT})$, light microscopy, and $\mathrm{X}$-ray microanalysis. The micro-CT showed that the screwthreads and typical implant configuration were well maintained through the installation procedure. Overall, histological responses showed that the titanium-coated implants were well tolerated and caused no atypical tissue response. In addition, the bone was seen in direct contact with the titanium-coated layer. The X-ray microanalysis results confirmed the light microscopical data. In conclusion, the obtained results proof the final use of titanium-coated
\end{abstract}

M. M. Shalabi · J. G. C. Wolke · V. M. J. I. Cuijpers

J. A. Jansen $(\square)$

Department of Periodontology and Biomaterials, Dentistry 309,

Radboud University Nijmegen Medical Center, P.O. Box 9101,

6500 HB Nijmegen, The Netherlands

e-mail: j.jansen@dent.umcn.nl
PMMA implants for evaluation of the bone-implant response using $\mu \mathrm{CT}$. However, this study also confirms that for a proper analysis of the bone-implant interface the additional use of microscopical techniques is still required.

\section{Introduction}

A successful oral implant is characterized by the occurrence of a direct contact between the surrounding bone and implant surface. Qualitative and quantitative evaluation of the peri-implant tissues around retrieved implants is classically done by means of light microscopy to confirm this required bone response. Different techniques are available to prepare histological sections as well as different staining procedures can be used to obtain information about the specific cellular and tissue response. However, a disadvantage of histological evaluation is that it provides only two-dimensional information. High-resolution threedimensional data of configurations with a multifaceted structural design, like oral implants, can be obtained by using microfocus computer tomography $(\mu \mathrm{CT})$ [1]. Analysis of the bone response around titanium implants by $\mu \mathrm{CT}$ has been found to be highly reliable for determining bone mass and bone density parameters. For example, in a recently published study, $89 \%$ matching in bone area measurements was observed comparing $\mu \mathrm{CT}$ slices with light microscopical sections [2]. On the other hand, metallic implants cause so-called streaking artifacts due to scattering of X-rays, which prevents an accurate evaluation of the interfacial bone-to-implant contact [3, 4]. Although, the placement of an aluminum filter between detector and specimens can suppress this phenomenon, it cannot be 
completely avoided [2]. A better solution for this problem is the use of synchrotron radiation microtomography $(\mathrm{SR} \mu \mathrm{CT})$. Due to the microenergitic X-rays as used in this technique, scattering can be avoided, which results in a higher sensitivity of bone detection near the implant surface and allows the quantification of the direct bone response [5]. Unfortunately, $\mathrm{SR} \mu \mathrm{CT}$ is not easy accessible and the procedure is also very time consuming.

In view of the above mentioned, it has been suggested that the use of thin titanium coatings deposited on a polymeric implant can offer an alternative option for analyzing bone-implant contact using $\mu \mathrm{CT}$-imaging [2]. In the past, titanium-coated polymeric implants were already successfully used for transmission electron microscopic analysis of the cell and tissue response $[6,7]$ and ultrastructural study of epithelial cell attachment to implant materials $[7,8]$.

Consequently, the aim of the current study is to investigate the bone behavior by $\mu \mathrm{CT}$ and light microscopy using titanium-coated PMMA implants.

\section{Materials and methods}

Implants

Ten conically-shaped screw designed PMMA implants were used. All implants measured $10 \mathrm{~mm}$ in length and had a diameter of $4.6 \mathrm{~mm}$. The implants were copied and prepared with a lathe out of PMMA rod completely analog to metallic implants (Biocomp ${ }^{\circledR}$ Industries, Dordrecht, The Netherlands). Subsequently, all ten implants were coated with a 400-500 nm thick layer of titanium (Ti) (Fig. 1).
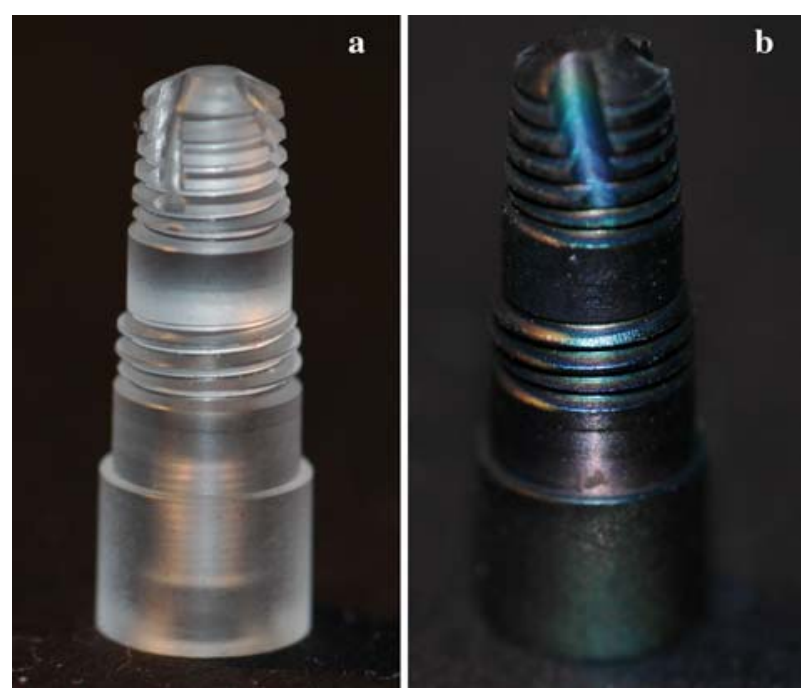

Fig. 1 Macroscopic pictures of a non-coated PMMA implant (A) titanium-coated PMMA implant (B). The titanium coating has a shiny, gray-black appearance
The Ti layer was deposited using a radio frequency magnetron-sputtering unit (Edwards ESM 100). During the sputtering process, a commercially pure Ti target was used. Pressure was kept at $5.0 \times 10^{-3}$ mbar using argon gas $(4 \mathrm{~L} /$ h), and the power level was set at $200 \mathrm{~W}$. The Ti target was sputter cleaned before deposition. The target was considered clean when the plasma turned from pink to blue, resulting from blue light emitting $\mathrm{Ti}$ in the plasma. The PMMA implants were sputtered for $30 \mathrm{~min}$. Finally, they were autoclaved for $15 \mathrm{~min}$ at a temperature of $121{ }^{\circ} \mathrm{C}$ before use in the experimental animal study.

Animal model and implantation procedure

Ten healthy mature (2-4 years of age) female Saanen goats, weighing about $60 \mathrm{~kg}$ were used in this study. Before surgery blood samples of the goats were taken to ensure that the animals were Caprine Arthritis-Encephalitis (CAE/CL) free. The animals were housed in a stable. National guidelines for the care and use of laboratory animals were observed.

The operation was performed under general anesthesia and was induced by an intravenous injection of pentobarbital and maintained by $2-3 \%$ ethrane through a constant volume ventilator, administered through an endo-tracheal tube. The goats were connected to a heart monitor. To reduce the risk of peri-operative infection, the goats were treated according to the following doses of antibiotics: during the operation: $3 \mathrm{~mL} / 50 \mathrm{~kg}$ s.c. Albipen ${ }^{\circledR} 15 \%$, one and three day after the operation: $7.5 \mathrm{~mL} / 50 \mathrm{~kg}$ s.c. Albipen ${ }^{\circledR}$ LA.

All implants were placed into the tibia of the right or left hind limbs of the goats. Therefore, the animals were immobilized on their back and the hind limbs were shaved, washed and disinfected with povidone-iodine. Then, a longitudinal incision was made on the tibia of the left or right side and the bone were exposed. Subsequently, a hole was drilled in the tibia with a consecutive series of drills to a final diameter of $4.6 \mathrm{~mm}$. The bone preparation was performed with a gentle surgical technique, using low rotational drill speeds (maximum $800 \mathrm{rpm}$ ) and continuous internal cooling. After preparation, the hole was irrigated and then packed with sterile cotton gauze to stop bleeding. Thereafter, the implant was press-fitted into the hole. Only one implant was inserted in each goat.

After placement of the implant, the soft tissues were closed in separate layers using resorbable Vicryl 3-0 sutures. Evaluation of the bone fixation was planned at an implantation period of 12 weeks. At the end of the implantation period the goats were killed by an overdose of Nembutal $^{\circledR}$ and the implants with surrounding tissue retrieved for histological evaluation and $\mu \mathrm{CT}$ analysis. 
Micro-CT evaluation

Implants were made of PMMA in order to allow the use of micro-CT. Earlier studies have already shown that microCT cannot be used to evaluate the bone response in close proximity of full metallic or full ceramic implants. Scattering occurs at the implant surface, which excludes proper evaluation. This problem can be avoided by making use of polymeric implants (feasibility has been confirmed in previous studies) [2].

For micro-CT evaluation a 3D analysis of bone formation was done.

After sacrificing the animals, the tibia including the implants were harvested immediately and fixed in $4 \%$ formaldehyde and dehydrated in ethanol. Subsequently, the specimens were wrapped in Parafilm ${ }^{\circledR}$ to prevent drying during scanning and placed in the middle of a cylindrical sample holder. Then, high-resolution scanning with a pixel size of $18.70 \mu \mathrm{m}$ was performed at energy of $100 \mathrm{kV}$ and intensity of $98 \mu \mathrm{A}$ (SkyScan-1072, Skyscan n.v., Aartselaar, Belgium). Cone beam reconstruction (version 2.15, Skyscan $^{\circledR}$ ) was performed on the 452 projected files. The number of cross-sections was set to cover the entire length of the implant. The micro-CT 3D-Creator software was used to make a 3D-reconstruction from the obtained stack of reconstructed files.

\section{Histological procedures}

Subsequent to $\mu \mathrm{CT}$-scanning, the specimens were cut to smaller size suitable for histological processing. Each specimen contained one implant site with surrounding bone. The specimens were then dehydrated in increasing ethanol concentrations and embedded (non-decalcified) in methyl methacrylate (MMA) for 4 weeks. After polymerization in MMA thin $(10 \mu \mathrm{m})$ non-decalcified sections were prepared with a modified diamond blade sawing microtome technique. These sections were made perpendicularly on the longitudinal axis of the implant. The sections were stained with methylene blue/basic fuchsin and examined with a light microscope.

\section{$\mathrm{X}$-ray microanalysis}

Following histological sectioning, the surface of the remaining part of the tissue block was polished with 4,000 grit silicon carbide sandpaper. Subsequently, the blocks were cleaned with $70 \%$ alcohol and carbon coated. Specimens were examined by scanning electron microscope (XL30 ESEM FEG, Philips, Eindhoven, The Netherlands) in backscatter mode at $20 \mathrm{kV}$, with an attached X-ray microanalysis system (EDAX with software, EDAX BV, Tilburg, The Netherlands).

\section{Results}

Throughout the experimental test periods, all animals appeared to be in good health. At sacrifice, no clinical signs of inflammation or adverse reaction were observed around the implants.

\section{Micro-CT evaluation}

The 3D reconstructed representations showed clearly the implants surrounded by cortical bone. Overall, the screwthreads and typical implant configuration were well maintained through the installation procedure. No streaking artefacts were present. The bone was found to be grown into the screw-threads and bone conduction into the marrow cavity was seen (Fig. 2). Evidently, the titanium coating was not thick enough to allow visualization of the implant part that was positioned into the medullar cavity.

\section{Histological description}

A short embedding procedure prevented serious distortion of the bulk of the PMMA implants due to the required use of organic solvents.

The histological evaluation demonstrated that the titanium-coated implants were well tolerated by the tissues. In the cortical compartment of the tibia, bone was observed in close contact with the titanium layer, which could easily be recognized and appeared to cover the implant surface for almost $100 \%$ (Fig. 3). The bone-titanium coating contact was almost continuous (Fig. 4A) and only occasionally remodeling lacunas (Fig. 4B) or an intervening fibrous tissue layer were seen. When fibrous tissue was present in the interface, this could frequently be associated with a lacking titanium coating (Fig. 4C). The bone around the implants showed a very organized structure in which osteons could be recognized. At the crestal side, the implants were always covered by newly deposited bone. At the apical side the implants penetrated into the medullar cavity. Ingrowth of bone along the implant surface and into the medullar cavity had occurred. In the bone marrow, no sign of an inflammatory response indicating a foreign body reaction was seen (Fig. 5).

X-ray microanalysis

Backscatter electron microscopy confirmed the light microscopical data. The PMMA material of the implant could be recognized as well as the titanium coating that covered the implant surface. Bone was seen in close contact with the major part of the implant surface. Figure 6A shows a cross-section where bone is not in direct contact with the titanium coating. Figure $6 \mathrm{~B}-\mathrm{E}$ show a mapping of 


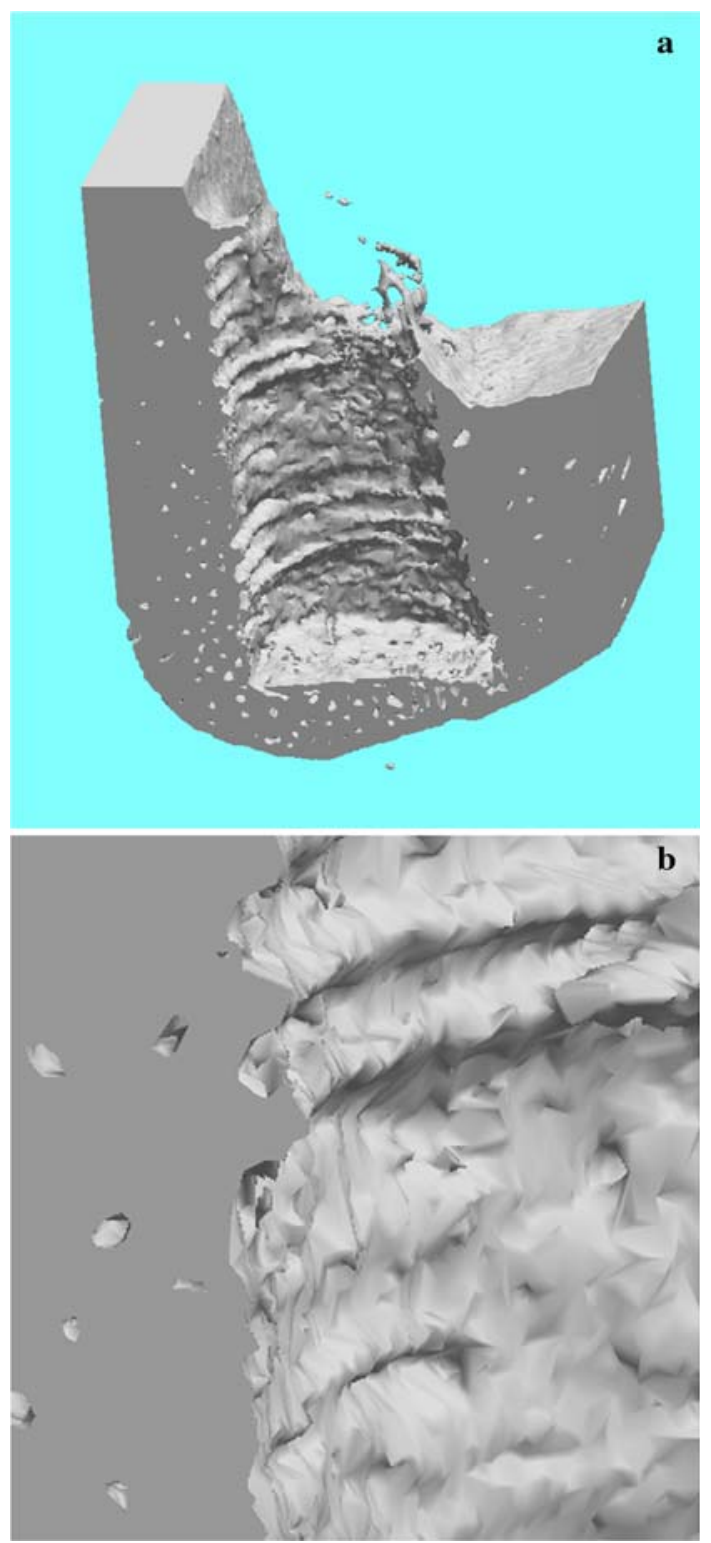

Fig. 2 Micro-computer tomography pictures showing the bone appearance after installation of the PMMA coated implant by a press-fit approach. (A) The implant penetrated into the medullar cavity and ingrowth of bone at the endosteal side can be observed. (B) The screw-threads as well as the smooth implant surface can be recognized

the PMMA implant-bone interface with regard to the presence of titanium, calcium, phosphorus, and carbon. The presence of calcium and phosphorus indicates the presence of bone and carbon indicates the coating as deposited onto the tissue block as required for backscatter electron microscopy. An integral mapping, as depicted in Fig. $6 \mathrm{~F}$, verifies that a gap existed between implant and bone, which indicates the presence of fibrous tissue. In areas with direct bone contact, EDS mapping confirmed that the implant was indeed in contact with the bone.

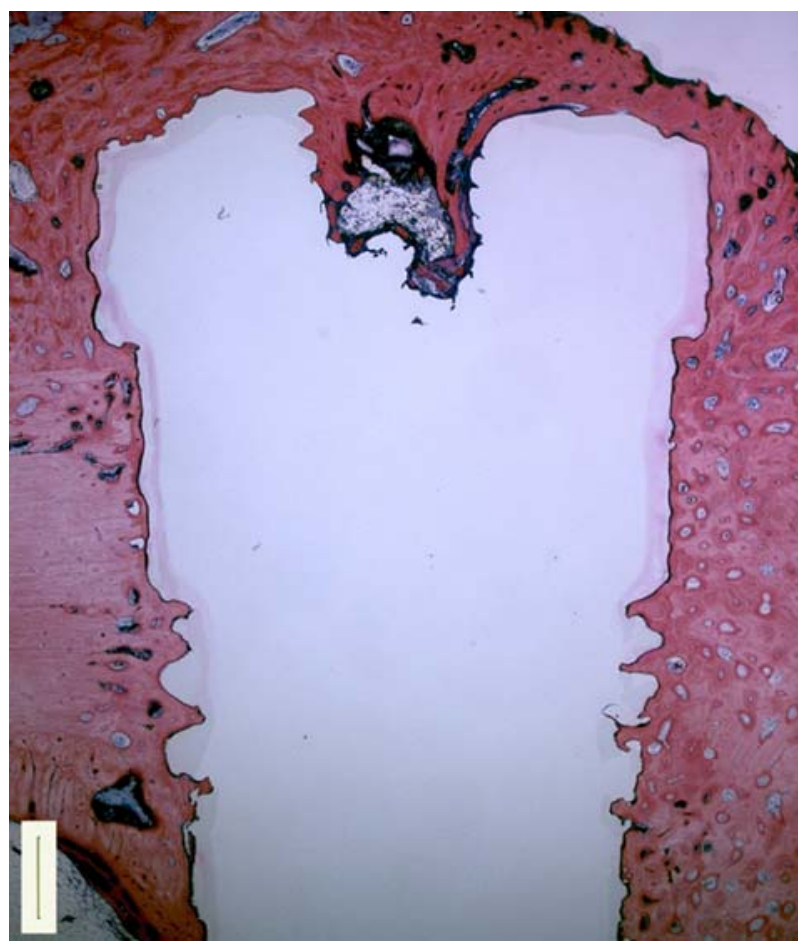

Fig. 3 Histological picture of a titanium coated PMMA implant. The implant is surrounded by bone tissue in close contact with the titanium coating, which is visible as a thin black line of the outer surface of the implant. Magnification $1.6 \times$, bar $=625 \mu \mathrm{m}$

\section{Discussion}

The aim of the present study was to determine whether the use of titanium-coated polymeric implants allows an accurate examination of the bone implant interface by $\mu \mathrm{CT}$ analysis. The obtained data were compared with light microscopical and scanning electron microscopical (elemental mapping) data.

The results indicated that the resolution of $\mu$ CT-images is still significantly less compared with both used microscopical techniques, which excludes evaluation at the cellular level. In view of this, additional visualization approaches are still needed for a proper complete study of the bone-implant response.

Previous studies already confirmed that the composition of thin magnetron sputtered titanium coatings is very similar to the surface composition of bulk titanium implants [9]. Rutherford backscattering spectroscopy and Xray photoelectron spectroscopy indicated that sputtered titanium coatings consist of titanium and oxygen in amounts of 1:1. Also, the adhesion property of this type of coating is sufficient to withstand continuous stretching at a frequency of $1 \mathrm{~Hz}$ and a magnitude of $1,000 \mu$ strain.

The overall bone response to titanium coatings is very similar to other studies with titanium-coated polymeric 

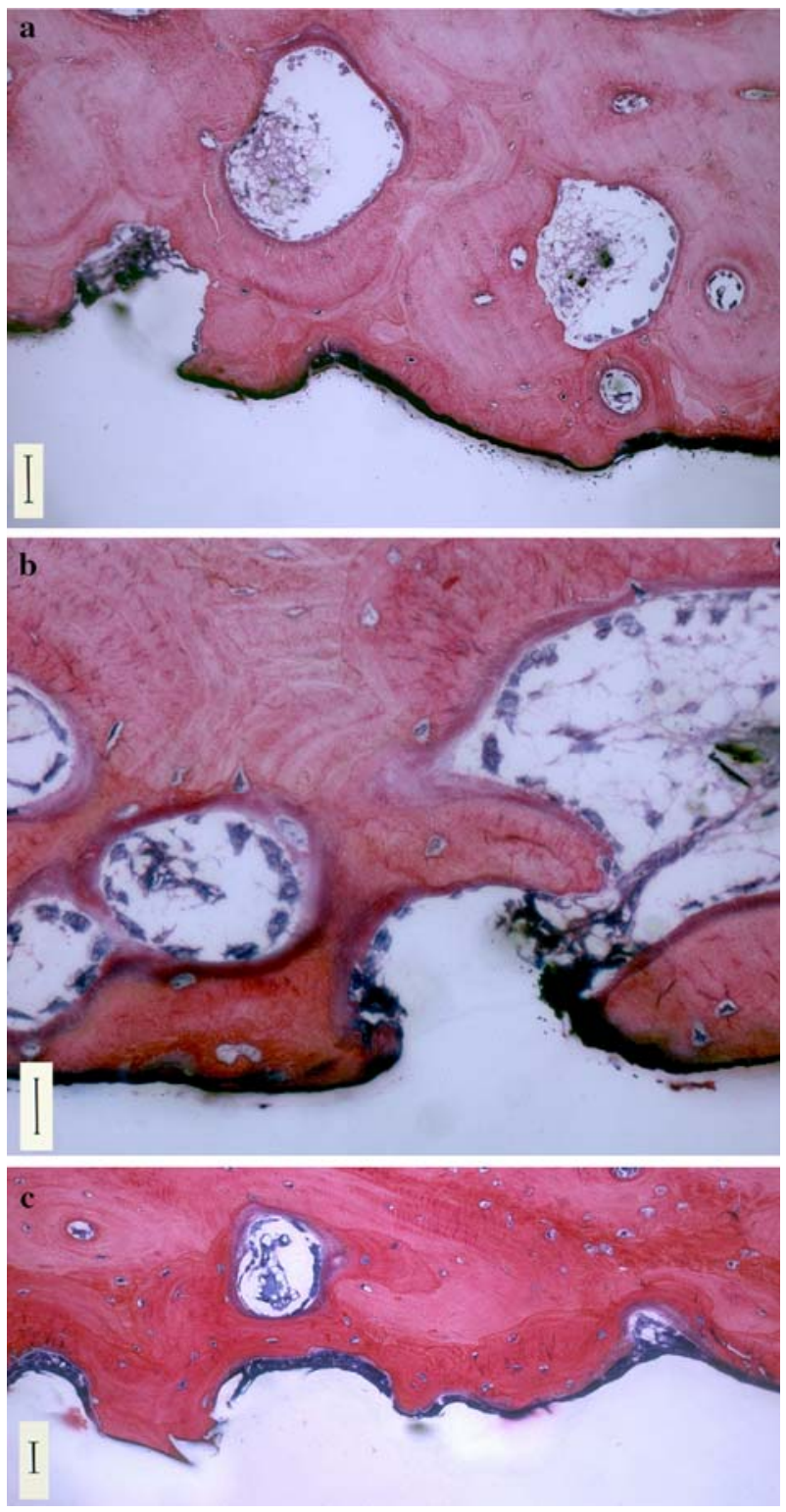

Fig. 4 Histological section of titanium-coated implant showing clearly the titanium layer. (A) the titanium layer was covered almost completely by bone, (B) occasionally remodeling lacunas were present. Original magnification $10 \times$, bar $=100 \mu \mathrm{m}$, and $(\mathbf{C})$ in areas where the coating was lacking, the implant surface was surrounded by fibrous tissue (blue layer). Magnification 20×, bar $=50 \mu \mathrm{m}$

implants. For example, Albrektsson et al. [6] used cylindrical, non-threaded polycarbonate plastic implants coated with titanium or gold, which were inserted for 12 weeks into the tibia of rabbits. The thickness of coating was 200$300 \mathrm{~nm}$. Using transmission electron microscopy, the bone surrounding the titanium-covered plastic core was shown to possess "normal" ultrastructural characteristics. At the titanium interface, the last 2 or 3 lamellae of bone became arranged parallel to the surface of the central plastic plug and not concentrically as in Haversian systems. The min-

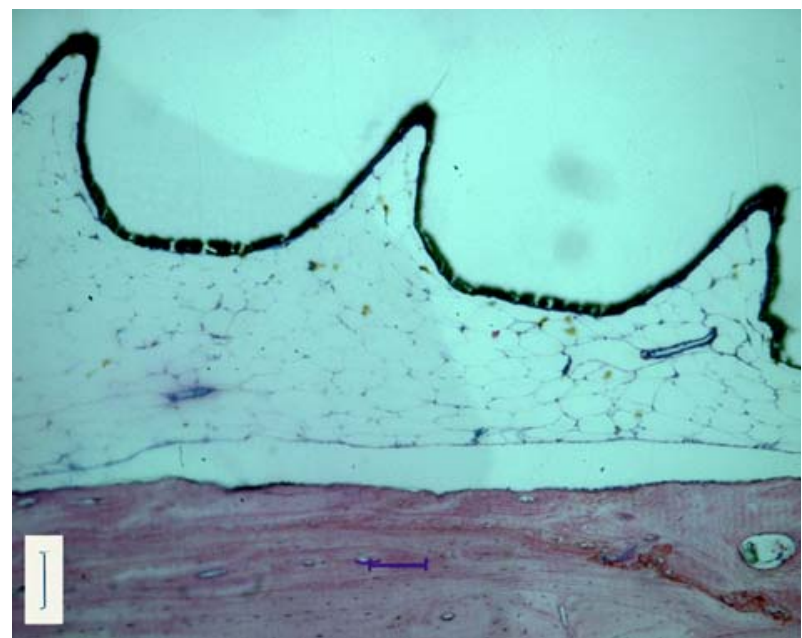

Fig. 5 The part of the implant that penetrated into the medullar cavity did not evoke any sign of an inflammatory response. Original magnification $10 \times$, bar $=100 \mu \mathrm{m}$

eralization was reduced close to the interface $(0.1-0.5 \mu \mathrm{m}$ from the metal border) and the collagen bundles became replaced by filaments, randomly arranged close to the interface. The last $20-40 \mathrm{~nm}$ from the titanium surface lacked distinct collagen filaments. This zone was observed to consist of partly calcified amorphous ground substance and partly proteoglycans and glucoseaminoglycans. No fibrous tissue was interposed between the bone and titanium surface. These results were confirmed in several follow-up studies of the same group, where titanium coated implants were compared with zirconium [10] and stainless steel coatings [11].

Considering the intervening fibrous tissue layer in areas where the coating is lacking, our findings corroborate with a previous study of Ooms et al. [12]. They injected PMMA bone cement into cortical bone defects as made into the tibia of goats. After 2 weeks of implantation, fibrous tissue formation was observed at the bone-PMMA interface, which was still present after 12 weeks of implantation. It has to be emphasized that the fibrous tissue response around this injected PMMA material was more enhanced compared to our exposed PMMA surface. Probably, this is due to the manufacturing process of our implants. The current implants were machined with a lathe out of pre-polymerized PMMA rods, while in the Ooms study the PMMA implants had to polymerize in situ, which results in prolonged release of cytotoxic monomer. This explanation is supported by other studies [13-16], who all used pre-polymerized implants, which evoked a moderate non-compatible bone response characterized by the occurrence of reduced bone contact and a thin separating fibrous tissue layer.

In our experiment, a conventional press-fit surgical technique was used for the installation of the implants. Occasionally, we experienced that increased force was 
Fig. 6 Back scatter image and $\mathrm{X}$-ray microanalytical mapping of a titanium coated PMMA implants. (A) The implant with the titanium coating (white line) can be recognized. Bone surrounds the implant. Mapping for titanium $(\mathbf{B})$, calcium $(\mathbf{C})$, phosphorus (D), and carbon (E). (F) An integral image in which all different mappings are combined shows the presence of a bone-free zone at the implant interface
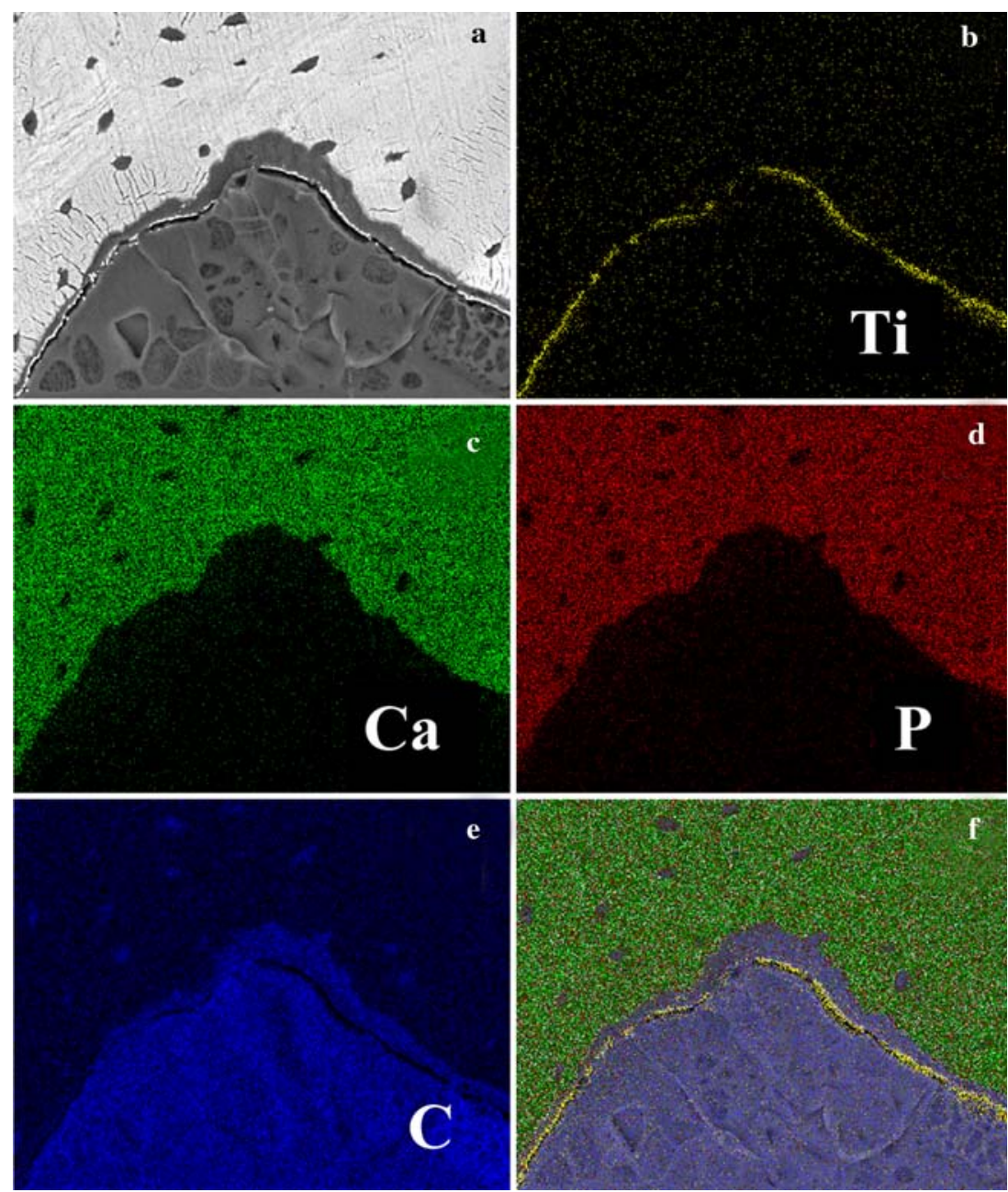

required to get the implants in the proper position. This might be the reason for the locally observed absence of the titanium coating. Previous pilot studies confirmed that the Titanium coating is not dissolving or detaching after storage in aqueous solution. Apparently, the tibial cortex of a goat is not the most optimal location for titanium-coated PMMA implants and low density trabecular bone, like as present in the femoral condyle or maxilla, has to be preferred.

Various microscopical techniques can be used to study the tissue reaction to implants, including light microscopy, scanning electron microscopy, transmission electron microcopy and confocal laser scanning microscopy. All these techniques provide information at the cellular level, but do not provide information about the elemental composition. X-ray mapping is a technique that exists already for more than 40 years whereby an image is formed using an X-ray signal in order to illustrate the elemental distribution within a tissue sample [17]. Under certain conditions, X-ray microanalysis is of special value in studies dealing with bone apposition on implants. The results as obtained in the current study prove again that scanning electron microscopy in combination with X-ray microanalysis is very valuable to prove the interfacial composition, i.e. the presence of bone.

Micro-CT is a non-destructive technique for visualizing bone-to implant response. Without the need of any specimen preparation, three-dimensional images of the samples can be produced that can be rotated and viewed from any angle. An additional advantage is that sections of the sample can be made in a non-destructive way in all directions for visualizing the bone response in a specific area. In addition, quantitative characterization of the bone response is possible. For example, bone volume, trabecular thickness, trabecular number and trabecular spacing can be measured [18]. A limitation is that the resolution of micro-CT is at the supracellular level and cannot be used to obtain detailed information about the bone response at the cellular level.

In conclusion, the obtained results prove the final use of titanium coated PMMA implants for evaluation of the bone-implant response using $\mu \mathrm{CT}$. However, this study also confirms that for a proper analysis of the bone-implant interface the additional use of microscopical techniques is still required. 


\section{References}

1. H. Van OOSTERWYCK, J. DUYCK, J. Van der SLOTEN, G. Van Der PERRE, J. JANSEN, M. WEVERS and I NAERT, $J$. Oral Implantol. 26 (2000) 5

2. N. STOPPIE, J. P. Van Der WAERDEN, J. A. JANSEN, J. DUYCK, M. WEVERS and I. E NAERT, Clin. Implant Dent. Relat. Res. 7 (2005) 87

3. R. BERNHARDT, D. SCHARNWEBER, B. MULLER, P. THURNER, H. SCHLIEPHAKE, P. WYSS, F. BECKMANN, J. GOEBBELS and H WORCH, Eur. Cells Mater. 7 (2004) 42

4. Y. S. Park, K. Y. Yi, I. S. Lee and Y. C. Jung, Clin. Oral Implants Res. 16 (2005) 156

5. R. BERNHARDT, J. Van DEN DOLDER, S. BIERBAUM, R. BEUTNER, D. SCHARNWEBER, J. JANSEN, F. BECKMANN and H WORCH, Biomaterials 26 (2005) 3009

6. T. Albrektsson, P. I. Branemark, H. A. Hansson, B. Ivarsson and U. Jonsson, Ultrastructural Analysis of the Interface Zone of Titanium and Gold Implants in Clinical Application of Biomaterials., edited by A. J. C. Lee, T. Albrektsson and P. I. Branemark (John Wiley \& Sons Ltd, 1982)

7. J. A. JANSEN, J. R De WIJN, J. M. WOLTERS-LUTGERHORST and P. J. Van MULLEM, J. Dent. Res. 64 (1985) 891

8. B. CHEHROUDI, T. R. GOULD and D.M. BRUNETTE, $J$. Biomed. Mater. Res. 25 (1991) 387
9. X. F. WALBOOMERS, W. J. HABRAKEN, B. FEDDES, L. C. WINTER, J. D. BUMGARDNER and J. A JANSEN, J. Biomed. Mater. Res. A 69 (2004) 131

10. T. ALBREKTSSON, H. A. HANSSON and B IVARSSON, Biomaterials 6 (1985) 97

11. T. ALBREKTSSON and H. A HANSSON, Biomaterials 7 (1986) 201

12. E. M. OOMS, J. G. WOLKE, M. T. Van De HEUVEL, B. JESCHKE and J. A JANSEN, Biomaterials 24 (2003) 989

13. P. SCHAFFNER, J. MEYER, M. DARD, R. WENZ, B. NIES, S. VERRIER, H. KESSLER and M KANTLEHNER, J. Mater. Sci. Mater. Med. 10 (1999) 837

14. Y. L. LIU, J. SCHOENAERS, K. D. K. GROOT, J. R. WIJN and E SCHEPERS, J. Mater. Sci. Mater. Med. 11 (2000) 711

15. M. FINI, G. GIAVARESI, N. N. ALDINI, P. TORRICELLI, R. BOTTER, D. BERUTO and R GIARDINO, Biomaterials 23 (2002) 4523

16. A. J. AHO, M. HAUTAMAKI, R. MATTILA, P. ALANDER, N. STRANDBERG, J. REKOLA, J. GUNN, L. V. LASSILA and P. K VALLITTU, Cell Tissue Bank. 5 (2004) 213

17. D. C. Sigee, A. J. Morgan, A. T. Sumner, A. Warley (editors) Xray Microanalysis in Biology; Experimental Techniques and Applications, (Cambridge University Press: New York, 1993)

18. T. HILDEBRAND, A. LAIB, R. MULLER, J. DEQUEKER and P RUEGSEGGER, J. Bone Miner. Res. 14 (1999) 1167 